\title{
Review on the role of glutathione on oxidative stress and infertility
}

\author{
Oyewopo Adeoye ${ }^{1}$, Johnson Olawumi ${ }^{1}$, Adeleke Opeyemi ${ }^{2}$, Oyewopo Christiania ${ }^{3}$ \\ ${ }^{1}$ Department of Anatomy, College of Health Sciences, University of Ilorin, Kwara State, Nigeria \\ 2 Department of Anatomy, College of Health Sciences, Osun State University, Osogbo, Nigeria \\ ${ }^{3}$ Department of Anesthesia, University of Ilorin Teaching Hospital, Ilorin, Kwara State, Nigeria
}

\begin{abstract}
Infertility is a global health problem and it is one of the most stressful conditions amongst married couples. Even though not lethal, it has been described as a radical life changing problem that carries with it significant psychological trauma. Infertility can be caused by various problems and sometimes it is not possible to establish a cause. Oxidative stress, which arises from an imbalance between reactive oxygen species (ROS) and protective antioxidants, influences the entire reproductive lifespan of men and women. ROS can modulate cellular functions, and oxidative stress can disturb the intracellular milieu, resulting in diseased cells or endanger cell survival. Under normal conditions, antioxidants act to oppose ROS production, scavenging existing free radicals and promoting the repair of ROS-induced damage to cell structures. At controlled levels, oxidative stress facilitates some physiological reproductive functions but at higher levels it is implicated in pathological processes in the reproductive tract that contribute to infertility and poor pregnancy outcomes. As high levels of reactive oxygen species and low antioxidant status have been implicated in conditions contributing to infertility, treatment based on strategies to boost the exhausted antioxidant defense of the reproductive microenvironment is intuitive. Glutathione is a natural body antioxidant, which helps preserve all other antioxidants. It is present in both the male and female gametes and its level varies widely. This study reviews the role oxidative stress plays in both male and female infertility, and the antioxidant action of glutathione on infertility.
\end{abstract}

Keywords: infertility, oxidative stress, glutathione, reactive oxygen species

\section{INTRODUCTION}

Infertility is a problem of large magnitude, and is one of the most stressful conditions among married couples (Agarwal \& Prabakaran, 2005). Even though it is not lethal, it has been described as a radical life changing problem that carries with it significant psychological trauma (Uadia \& Emokpae, 2015). Infertility can be caused by different problems, and sometimes it is not possible to establish a cause. There may be a single cause in either partner or a combination of problems that may prevent conception occurring or a pregnancy continuing. Both men and women can have infertility problems, which is the case in about $20 \%$ of infertile couples. In around $15 \%$ of cases, no cause of infertility is identified in either partner and this is referred to as unexplained infertility. Combined female and male factor is responsible for $20-30 \%$ of cases. If the results of a standard infertility examination are normal, a diagnosis of unexplained or idiopathic infertility is assigned (Eskandari \& Cadieux, 2003; Sekhon et al., 2010). However, when causes are identified among women, they most commonly include irregular ovulation, endometriosis and obstructed fallopian tubes; while among men, the most common cause are sperm disorders. Oxidative stress has a well-established role in the pathogenesis of explained and unexplained infertility, which is seen to affect $15 \%$ of couples (Eskandari \& Cadieux, 2003; Sekhon et al., 2010).

Oxidative stress, which arises from an unbalance between reactive oxygen species (ROS) and protective antioxidants, influences the entire reproductive lifespan of men and women (Sekhon et al., 2010). Reactive oxygen species may act as key signaling molecules in physiological processes, but in excess, uncontrolled levels may also mediate pathological processes involving the reproductive tract/reproduction. ROS can modulate cellular functions and oxidative stress (OS) can disturb the intracellular milieu, resulting in diseased cells or endanger cell survival. Under normal conditions, antioxidants act to oppose ROS production, scavenging existing free radicals and promoting repair of ROS -induced damage to cell structures (Agarwal \& Allamaneni, 2004).

Glutathione is the mother of all antioxidants, the master detoxifier and maestro of the immune system (Hyman, 2011). It is one of the major endogenous antioxidant produced by cells participating directly in the neutralization of free radicals and reactive oxygen species, as well as maintaining exogenous antioxidants such as vitamins $C$ and $E$ in their reduced forms (Drigen, 2000).

This paper will review the role oxidative stress plays in both male and female infertility and the antioxidative action of glutathione on infertility and how the level of glutathione can be raised in the body.

\section{Oxidative Stress and Infertility}

Infertility is the term used to describe a couple's failure to conceive, despite having engaged in regular and unprotected intercourse for a year (Robertson, 2015). It also includes the inability to carry a pregnancy to the delivery of a live baby (WHO, 1992). The World Health Organization (WHO, 1991) estimates that $8-12 \%$ of couples worldwide experience some forms of infertility during their reproductive lives, thus affecting 50-80 million couples, with 2030 million in Africa. Therefore, it has been extrapolated that 3-4 million Nigerian couples are affected (Sule et al., 2008). Even though infertility is not life threatening, it has been described as a radical life changing problem because it carries with it significant psychological trauma (Umezulike \& Efetie, 2004). The prevalence of infertility in Sub-Saharan Africa ranges from $20-40 \%$. Although, the African socio-cultural setting has so far focused on females only, fertility problems are shared by both males and females (Uadia \& Emokpae, 2015).

Oxidative stress (OS) affects the quality of gametes and the way in which they interact. Oxidative stress arises from an unbalance between pro-oxidant molecules generated from aerobic metabolism and protective antioxidants (Sekhon et al., 2010). Free radicals such as ROS influence oocytes, spermatozoa and embryos and their environments. The microenvironments associated with follicular fluid, hydrosalpingeal fluid and peritoneal fluid have a direct bearing on oocyte quality, sperm oocyte interaction, sperm-mediated oocyte activation, implantation and early embryo development. OS affects early embryo development and implantation, which in turn affects pregnancy rates (Agarwal et al., 2005a;b). Infertility is a problem of 
large magnitude and OS has been investigated as a causative factor.

\section{Oxidative stress and male infertility}

Infertility probably affects at least one couple in six, and male factor infertility represents $30 \%$ of the diagnosis in infertile couples (Makker et al., 2009). In Nigeria, the male factor is responsible for $40-50 \%$ of all infertility, although it varies from on region to region. The commonest singly defined cause of male factor infertility is sperm dysfunction (Hull et al., 1985). High levels of ROS biomarkers were detected in semen samples from $25-40 \%$ of infertile men (Makker et al., 2009). This may mean that ROS may be responsible, or it may be a contributory factor to the infertility been experienced by such individual; nevertheless, ROS have a physiological role in normal sperm function, acrosome reaction, hyperactivation, motility and capacitation of spermatozoa. Excessive levels of ROS may arise from immotile or morphologically abnormal spermatozoa and leukocytes (Sekhon et al., 2010).

Spermatozoa are vulnerable to ROS because their plasma membrane and cytoplasm contain large amounts of polyunsaturated fatty acids (Alvarez \& Storey, 1995), resulting in a decrease in sperm motility, presumably by a rapid loss of intracellular ATP, causing axonemal damage (de Lamirande \& Gagnon, 1992), a decrease in sperm viability and an increase in mid-piece morphology defects, with deleterious effects on sperm capacitation and acrosome reaction. Lipid peroxidation of the sperm membrane is the key mechanism of this ROS-induced sperm damage, leading to infertility.

Excessive generation of ROS in the semen, by leukocytes as well as by abnormal spermatozoa, could be a cause of infertility (Sharma \& Agarwal, 1996). Hydrogen peroxide is the major ROS producer in human spermatozoa. Moderately elevated concentrations of hydrogen peroxide do not affect sperm viability but cause sperm immobilization, mostly via depletion of intracellular ATP and the subsequent decrease in axonemal proteins' phosphorylation (Kemal Duru et al., 2000; Misro et al., 2004). High concentrations of hydrogen peroxide induce lipid peroxidation and results in cell death (Agarwal \& Prabakaran, 2005).

A study reported that the levels of antioxidants in seminal plasma from infertile men were significantly lower than levels in fertile controls, and it was demonstrated that the levels of ROS produced by spermatozoa were negatively correlated with the quality of sperm in the original semen (Pasqualotto et al., 2000). However, pathological levels of ROS detected in semen of infertile men are more likely a result of increased ROS production, rather than a reduced antioxidant capacity of the seminal plasma (Zini et al., 1993). Virtually every human ejaculate is contaminated with potential sources of ROS such as leukocytes and abnormal spermatozoa. It follows that some spermatozoa will incur oxidative damage and a concomitant loss of function. Thus, the impact of ROS on male infertility is a question of degree rather than the presence or absence of the pathology.

\section{Oxidative stress and female infertility}

Female infertility affects an estimated 48 million women with the highest prevalence affecting people in South Asia, Sub Saharan Africa, North Africa/Middle East, Central Europe and Central Asia (Mascarenhas et al., 2012). Infertility affects women from around the world and the cultural and social stigma surrounding it varies. According to a study, the prevalence of female infertility ranges from $7 \%$ to $28 \%$ depending on the age of the woman (Yu \& Yap, 2003). Although the frequency and origin of different forms of infertility varies, $40-50 \%$ of the etiology of infertility is due to female causes (Duckitt, 2003).
At controlled levels, free radicals can exert physiological effects and mediate processes such as tissue remodeling, hormone signaling, oocyte maturation, folliculogenesis, tubal function, ovarian steroidogenesis, cyclical endometrial changes, germ cell function, pregnancy, normal parturition and initiation of preterm labor (Agarwal et al., 2005a;b). However, when ROS increase to pathological levels they are capable of inflicting significant damage to cell structures.

The pathological effects are exerted by various mechanisms including lipid damage, inhibition of protein synthesis and ATP depletion (Ray et al., 2004). Oxidative stress plays a role in the etiopathogenesis of endometriosis, polycystic ovarian disease, hydatidiform mole, tubal factor infertility and unexplained infertility. There is growing literature on the effects of oxidative stress involved in the pathophysiology of pre-eclampsia (Tranquilli et al., 2004), free induced birth defects (Loeken, 2004) and other situations such as abortions (Łagód et al., 2001).

Oxidative stress induces infertility in woman through a variety of mechanisms. Excess ROS in the follicle may overwhelm follicular fluid antioxidant defense and directly damage oocytes. The DNA of oocytes and spermatozoa may be damaged, leading to defective fertilizations. Even when fertilization is achieved, oxidative stress-induced apoptosis may result in embryo fragmentation, implantation failure, abortion, impaired placentation and congenital abnormalities (Agarwal et al., 2006). Excess reactive oxygen species may hinder the endometrium which normally functions to support the embryo and its development (Iborra et al., 2005). Oxidative stress may induce luteal regression and insufficient luteal hormonal support for the continuation of a pregnancy (Agarwal \& Allamaneni, 2004).

\section{The role of oxidative stress in some conditions that contribute to infertility \\ Polycystic Ovarian Syndrome (PCOS): PCOS is an} anovulatory cause of infertility in $6-10 \%$ of premenopausal women (Asunción et al., 2000). PCOS often can be characterized by hyper androgenism, hirsutism and oligomenorrhea or amenorrhea. Metabolic, endocrinological and cardiovascular disorders may coexist. Oxidative stress has been implicated in mediating the insulin resistance and increase in androgens seen in these patients (González et al., 2006).

A recent study by Kuşçu \& Var (2009) demonstrated increased MDA levels and upregulated SOD activity in patients' controls. MDA levels were highest in patients who exhibited insulin resistance. Insulin resistance and hyper glycemia are established as factors that increase oxidative stress. Fulghesu et al. (2002) evaluated the effect of $\mathrm{N}$-acetyl-cysteine (NAC), known to replenish stores of the antioxidant glutathione, on insulin secretion and peripheral insulin resistance in subjects with PCOS.

Endometriosis: Endometriosis-associated infertility remains one of the most frustrating clinical situations encountered by the gynecologist. Although endometriosis is a common diagnosis in infertile couples, there remains a great deal of uncertainty about the mechanism and treatment of infertility in these patients. Severe cases of endometriosis are thought to render a woman infertile by mechanical hindrance of sperm-egg union by adhesions, endometriomas and pelvic anatomy malformations. ROS production may be amplified in the setting of endometriosis due to menstrual reflux, which subjects the peritoneal cavity to pro inflammatory hemoglobin and heme molecules released from transplanted erythrocyte debris (Reubinoff et al., 1996). ROS are thought to promote the growth and adhesion of endometrial cells in the peritoneal cavity, contributing to the pelvic anatomical distortion known to cause infertility in endometriosis. Oxidative stress may have a role in promoting angiogenesis in ecto- 
pic endometrial implants by increasing vascular endothelial growth factor production (Park et al., 2006).

Altered molecular genetic pathways may also contribute to the effects of oxidative stress in the pathogenesis of endometriosis and endometriosis-associated infertility. Differential gene expression of ectopic and normal endometrial tissue has been identified, including differential gene expression of glutathione-S-transferase, an enzyme in the metabolism of the potent antioxidant glutathione (Wu et al., 2006). This suggests that altered molecular genetic pathways may determine the development of oxidative stress and its ability to induce cellular proliferation and angiogenesis in women with endometriosis.

Unexplained Infertility: The pathophysiology of unexplained infertility remains a scientific challenge. Elevated levels of ROS that disturb the redox balance within the body may be the root cause of infertility in women who do not have any other obvious cause. The ovum released from the ovary, the zygote or embryo and spermatozoa are vulnerable to damage inflicted by oxidative stress (Agarwal \& Allamaneni, 2004). Wang et al. (1997) compared ROS levels in the peritoneal fluid between women undergoing laparoscopy for infertility evaluation and fertile women undergoing tubal ligation, and demonstrated that higher levels of ROS exist in the peritoneal fluid aspirated from patients with unexplained infertility, compared to that measured within the peritoneal fluid of fertile women. Polak et al. (1999) analyzed peritoneal fluid samples obtained at laparoscopy and found that women with unexplained infertility had increased MDA concentrations and TAS, implicating the role of redox unbalance in its pathogenesis. Elevated ROS levels in patients with unexplained infertility implies exhausted antioxidant defense, resulting in the inability to scavenge ROS and neutralize their toxic effects.

\section{Glutathione: The master antioxidant}

Glutathione (GSH), tripeptide thiol is the major non-protein sulfhydryl compound in mammalian cells, known to have numerous biological functions. This thiol plays a prominent role in detoxification and antioxidation of exogeneous and endogenous compounds, as well as maintaining the intracellular redox status. It is a combination of three simple building blocks of protein or amino acids- cysteine, glycine and glutamine. Glutathione is a natural reservoir of reducing power, which can be quickly used by the cells as defense against oxidative stress. The sulfhydryl group (SH) of glutathione confers its protective action against oxidative damage. Glutathione exists in two forms: the reduced form (GSH) and the oxidized form (GSSG). The protective action of glutathione against reactive oxygen species (ROS) is facilitated by the interactions with its associated enzymes, such as glutathione peroxidase and glutathione reductase. In animal tissues, glutathione peroxidase, a selenium containing anti-oxidant enzyme, catalyzes the reduction of hydrogen peroxide and lipid peroxide in the presence of GSH, which is converted to GSSG. In turn, GSSG is reduced by glutathione reductase in the presence of nicotinamide adenine dinucleotide phosphate $[\mathrm{NAD}(\mathrm{P}) \mathrm{H}]$, which is generated mainly in the pentose phosphate pathway, as shown in the following equations:

$$
\begin{aligned}
& 2 \mathrm{GSH}+\mathrm{H}_{2} \mathrm{O}_{2} \longrightarrow \mathrm{GSSG}+2 \mathrm{H}_{2} \mathrm{O} \\
& \mathrm{GSSG}+\mathrm{NADPH}+\mathrm{H}^{+} \longrightarrow 2 \mathrm{GSH}+\mathrm{NADP}^{+}
\end{aligned}
$$

Glutathione is a widely distributed thiol in animal organisms, not only in somatic cells but also in the gametes.
In the body, the antioxidant defense capability consists of enzymatic and non-enzymatic systems, in which the latter is represented mainly by glutathione (Luberda, 2005). The body reproduces its own glutathione and it can be depleted by diet, pollution, toxins, medications, stress, trauma, aging, infections and radiation; and glutathione is normally recycled in the body.

The basic function of glutathione in the reproductive system is related to its interactions with other systems, as a preventive mechanism against ROS. Glutathione levels can be improved and optimized through the following ways: consuming sulphur-rich foods such as garlic, onions, cabbage, cauliflower, broccoli, etc., consuming bioactive whey protein found in non-pasteurized and non-industrially produced milk, which is a great source of cysteine and the amino acid building blocks for glutathione synthesis, doing exercise and taking a family of antioxidants which include vitamin $C$ and $E$ (in the form of mixed tocopherols), all working together to recycle glutathione (Nuttall et al., 1998).

\section{Glutathione and male infertility}

A glutathione deficiency can lead to instability of the sperm's mid piece resulting in defective motility (Hansen \& Deguchi, 1996; Ursini et al., 1999). It protects the plasma membrane from lipid peroxidation, scavenges superoxide and prevents oxygen formation. In a study consisting of infertile men with unilateral varicocele or genital tract inflammation, glutathione led to significant improvement in sperm quality (Lenzi et al., 2004).

The glutathione/reductase system forms an excellent protection against the lipid peroxidation of the spermatozoa plasma membrane. It scavenges lipid peroxides, thereby arresting the progressive chain reaction of lipid peroxidation. It also scavenges hydrogen peroxide $\left(\mathrm{H}_{2} \mathrm{O}_{2}\right)$, which is responsible for lipid peroxidation onset. Glutathione reductase stimulates the reduction of glutathione disulphide, to reduced glutathione, thereby recycling it.

\section{Glutathione and female infertility}

Glutathione shields eggs from damage caused by oxidative stress during folliculogenesis, and as such, egg quality is dependent on it. In fact, research has shown that oocytes with higher levels of intracellular glutathione produce healthier and stronger embryos (Mukherjee et al., 2014). Another study has shown that in younger years, women's ovaries have higher intracellular glutathione levels (Kankofer et al., 2013).

It has been reported that glutathione deficiency is related to premature ovarian aging and even ovarian cancer (Lim et al., 2013). Another study found that for women undergoing IVF, higher levels of glutathione in a woman's follicle translated into increased fertilization rates (Tola et al., 2013). In other studies, glutathione is shown to be an antiaging antioxidant which could have possible impact on egg health, one of the cells most affected by the aging process (Fujii et al., 2005). The protective action of follicle stimulating hormone on embryonic development is largely due to glutathione synthesis (Tsai-Turton \& Luderer, 2006).

Glutathione can reduce oxidative stress by fighting the formation of damaging free radicals in the reproductive system (Gardiner et al., 1998). It is the cell's primary antioxidant. Across the board, low levels of glutathione are a marker for disease and premature death. One of the areas of fertility, glutathione may have an impact on is the autoimmune issues. Glutathione is involved in regulating the genes that cause chronic inflammation. This may be helpful for those who are experiencing immunological miscarriages or if the body is rejecting one's mate's sperm. 


\section{CONCLUSION}

Oxidative stress occurs when the generation of reactive oxygen species (ROS) and other radical species overrides the scavenging capacity of antioxidants, either due to excessive ROS production or an inadequate availability of antioxidants. At controlled levels, oxidative stress facilitates some physiological reproductive functions but at higher levels it is implicated in pathological processes of the reproductive tract that contribute to infertility and poor pregnancy outcome. As high degrees of reactive oxygen species and low antioxidant status have been implicated in the conditions contributing to infertility, treatment based on strategies to boost the exhausted antioxidant defense of the reproductive microenvironment is intuitive.

Glutathione is the body's major antioxidant which helps in preserving all other antioxidants. It is a natural antioxidant present in both the male and female gametes, and its levels vary widely. It has been confirmed that it plays an important role in maintaining the biological value of germ cells, and it has been implicated in the fertilization process and early embryo development. The good thing is that the body can recycle glutathione if properly optimized, and it can also be destroyed.

\section{CONFLICT OF INTERESTS}

No conflict of interest has been declared.

\section{Corresponding author:}

Adeleke Opeyemi Samson

Department of Anatomy

College of Health Sciences

Osun State University

Osogbo, Nigeria

E-mail: opeyemi.adeleke@uniosun.edu.ng

\section{REFERENCES}

Agarwal A, Allamaneni SS. Role of free radicals in female reproductive diseases and assisted reproduction. Reprod Biomed Online. 2004;9:338-47. DOI: 10.1016/S1472-6483(10)62151-7 PMID: 15353087

Agarwal A, Prabakaran SA. Oxidative stress and antioxidants in male infertility: a difficult balance. Iran J Reprod Med. 2005;3:1-8.

Agarwal A, Gupta S, Sharma R. Role of oxidative stress in female reproduction. Reprod Biol Endocrinol. 2005a;3:28. PMID: 16018814 DOI: $10.1186 / 1477-7827-3-28$

Agarwal A, Gupta S, Sharma R. Oxidative stress and its implications in female infertility - a clinician's perspective. Reprod Biomed Online. 2005b;11:641-50. PMID: 16409717 DOI: $10.1016 / S 1472-6483(10) 61174-1$

Agarwal A, Said TM, Bedaiwy MA, Banerjee J, Alvarez JG. Oxidative stress in an assisted reproductive techniques setting. Fertil Steril. 2006;86:503-12. PMID: 16860798 DOI: $10.1016 /$ j.fertnstert.2006.02.088

Alvarez JG, Storey BT. Differential incorporation of fatty acids into and peroxidative loss of fatty acids from phospholipids of human spermatozoa. Mol Reprod Dev. 1995;42:334-46. PMID: 8579848 DOI: 10.1002/mrd.1080420311
Asunción M, Calvo RM, San Millán JL, Sancho J, Avila S, Escobar-Morreale HF. A prospective study of the prevalence of the polycystic ovary syndrome in unselected Caucasian women from Spain. J Clin Endocrinol Metab. 2000;85:24348. PMID: 10902790 DOI: $10.1210 /$ jcem.85.7.6682

de Lamirande E, Gagnon C. Reactive oxygen species and human spermatozoa. I. Effects on the motility of intact spermatozoa and on sperm axonemes. J Androl. 1992;13:368-78. PMID: 1331006

Drigen R. Metabolism and functions of glutathione in brain. Prog Neurobiol. 2000;62:649-71. PMID: 10880854 DOI: 10.1016/S0301-0082(99)00060-X

Duckitt K. Infertility and subfertility. Clin Evid. 2003;2003:2044-73. PMID: 12967463

Eskandari M, Cadieux M. Infertility. In: DeCherney $A H$, Nathan L, eds. Current Obstetric \& Gynecologic. Diagnosis \& Treatment. New York: McGraw Hill; 2003. p. 979-90.

Fujii J, Iuchi Y, Okada F. Fundamental roles of reactive oxygen species and protective mechanisms in the female reproductive system. Reprod Biol Endocrinol. 2005;3:45. DOI: $10.1186 / 1477-7827-3-43$

Fulghesu AM, Ciampelli M, Muzj G, Belosi C, Selvaggi $\mathrm{L}$, Ayala GF, Lanzone A. N-acetyl-cysteine treatment improves insulin sensitivity in women with polycystic ovary syndrome. Fertil Steril. 2002;77:1128-35. PMID: 12057717 DOI: $10.1016 /$ S0015-0282(02)03133-3

Gardiner CS, Salmen JJ, Brandt CJ, Stover SK. Glutathione is present in reproductive tract secretions and improves development of mouse embryos after chemically induced glutathione depletion. Biol Reprod. 1998;59:431-6. PMID: 9687318 DOI: $10.1095 /$ biolreprod59.2.431

González F, Rote NS, Minium J, Kirwan JP. Reactive oxygen species-induced oxidative stress in the development of insulin resistance and hyperandrogenism in polycystic ovary syndrome. J Clin Endocrinol Metab. 2006;91:33640. PMID: 16249279 DOI: $10.1210 /$ jc. $2005-1696$

Hansen JC, Deguchi Y. Selenium and fertility in animals and man--a review. Acta Vet Scand. 1996;37:19-30. PMID: 8659343

Hull MG, Glazener CM, Kelly NJ, Conway DI, Foster PA, Hinton RA, Coulson C, Lambert PA, Watt EM, Desai KM. Population study of causes, treatment, and outcome of infertility. Br Med J (Clin Res Ed). 1985;291:1693-7. DOI: $10.1136 / \mathrm{bmj} .291 .6510 .1693$

Hyman M. Glutathione: The Mother of All Antioxidants. The Blog. 2011. Available at: https://www.huffingtonpost.com/ dr-mark-hyman/glutathione-the-mother-of_b_530494. html. Accessed: 17/11/2017.

Iborra A, Palacio JR, Martinez P. Oxidative stress and autoimmune response in the infertile woman. Chem Immunol Allergy. 2005;88:150-62. PMID: 16129944 DOI: $10.1159 / 000087832$ 
Kankofer M, Wawrzykowski J, Giergiel M. Sex- and agedependent activity of glutathione peroxidase in reproductive organs in pre- and post-pubertal cattle in relation to total antioxidant capacity. Aging Clin Exp Res. 2013;25:365-70. PMID: 23740597 DOI: 10.1007/s40520-013-0056-3

Kemal Duru N, Morshedi M, Oehninger S. Effects of hydrogen peroxide on DNA and plasma membrane integrity of human spermatozoa. Fertil Steril. 2000;74:1200-7. PMID: 11119751 DOI: 10.1016/S0015-0282(00)01591-0

Kuşçu NK, Var A. Oxidative stress but not endothelial dysfunction exists in non-obese, young group of patients with polycystic ovary syndrome. Acta Obstet Gynecol Scand. 2009;88:612-7. PMID: 12673475 DOI: $10.1080 / 00016340902859315$

Łagód L, Paszkowski T, Sikorski R, Rola R. The antioxidantprooxidant balance in pregnancy complicated by spontaneous abortion. Ginekol Pol. 2001;72:1073-8. PMID: 11883212

Lenzi A, Sgrò $P$, Salacone $P$, Paoli D, Gilio B, Lombardo F, Santulli M, Agarwal A, Gandini L. A placebo-controlled double-blind randomized trial of the use of combined I-carnitine and I-acetyl-carnitine treatment in men with asthenozoospermia. Fertil Steril. 2004;81:1578-84. PMID: 15193480 DOI: $10.1016 /$ j.fertnstert.2003.10.034

Lim J, Lawson GW, Nakamura BN, Ortiz L, Hur JA, Kavanagh $\mathrm{TJ}$, Luderer $\mathrm{U}$. Glutathione-deficient mice have increased sensitivity to transplacental benzo[a]pyrene-induced premature ovarian failure and ovarian tumorigenesis. Cancer Res. 2013;73:908-17. PMID: 23135907 DOI: 10.1158/0008-5472.CAN-12-3636

Loeken MR. Free radicals and birth defects. J Matern Fetal Neonatal Med. 2004;15:6-14. PMID: 15101606 DOI: $10.1080 / 14767050310001650662$

Luberda $Z$. The role of glutathione in mammalian gametes. Reprod Biol. 2005;5:5-17. PMID: 15821775

Makker K, Agarwal A, Sharma R. Oxidative stress \& male infertility. Indian J Med Res. 2009;129:357-67. PMID: 19535829

Mascarenhas MN, Flaxman SR, Boerma T, Vanderpoel $\mathrm{S}$, Stevens GA. National, regional, and global trends in infertility prevalence since 1990: a systematic analysis of 277 health surveys. PLoS Med. 2012;9:e1001356. PMID: 23271957 DOI: $10.1371 /$ journal.pmed.1001356

Misro MM, Choudhury L, Upreti K, Gautam D, Chaki SP, Mahajan AS, Babbar R. Use of hydrogen peroxide to assess the sperm susceptibility to oxidative stress in subjects presenting a normal semen profile. Int J Androl. 2004;27:82-7. PMID: 15149465 DOI: 10.1046/j.0105-6263.2003.00451.x

Mukherjee A, Malik $H$, Saha AP, Dubey A, Singhal DK, Boateng S, Saugandhika S, Kumar S, De S, Guha SK, Malakar D. Resveratrol treatment during goat oocytes maturation enhances developmental competence of parthenogenetic and hand-made cloned blastocysts by modulating intracellular glutathione level and embryonic gene expression. J Assist Reprod Genet. 2014;31:229-39. PMID: 24305840 DOI: $10.1007 /$ s10815-013-0116-9
Nuttall SL, Martin U, Sinclair AJ, Kendall MJ. Glutathione: in sickness and in health. Lancet. 1998;351:645-6. PMID: 9500325 DOI: $10.1016 /$ S0140-6736(05)78428-2

Park JK, Song M, Dominguez CE, Walter MF, Santanam N, Parthasarathy S, Murphy AA. Glycodelin mediates the increase in vascular endothelial growth factor in response to oxidative stress in the endometrium. Am J Obstet Gynecol. 2006;195:1772-7. PMID: 17132480 DOI: $10.1016 /$ j.ajog.2006.07.025

Pasqualotto FF, Sharma RK, Nelson DR, Thomas AJ, Agarwal A. Relationship between oxidative stress, semen characteristics, and clinical diagnosis in men undergoing infertility investigation. Fertil Steril. 2000;73:459-64. PMID: 10688996 DOI: 10.1016/S0015-0282(99)00567-1

Polak G, Rola R, Gogacz M, Kozioł-Montewka M, Kotarski J. Malonyldialdehyde and total antioxidant status in the peritoneal fluid of infertile women. Ginekol Pol. 1999;70:135-40. PMID: 10390915

Ray SD, Lam TS, Rotollo JA, Phadke S, Patel C, Dontabhaktuni A, Mohammad S, Lee H, Strika S, Dobrogowska A, Bruculeri C, Chou A, Patel S, Patel R, Manolas T, Stohs S. Oxidative stress is the master operator of drug and chemically-induced programmed and unprogrammed cell death: Implications of natural antioxidants in vivo. Biofactors. 2004;21:22332. PMID: 15630201 DOI: 10.1002/biof.552210144

Reubinoff BE, Har-El R, Kitrossky N, Friedler S, Levi R, Lewin $A$, Chevion $M$. Increased levels of redox-active iron in follicular fluid: a possible cause of free radicalmediated infertility in beta-thalassemia major. Am J Obstet Gynecol. 1996;174:914-8. PMID: 8633668 DOI: $10.1016 / S 0002-9378(96) 70325-3$

Robertson S. Infertility Prevalence. News Medical Life Science. 2015. Available at: https://www.news-medical. net/health/Infertility-Prevalence.aspx. Accessed: $17 / 11 / 2017$.

Sekhon LH, Gupta S, Kim Y, Agarwal A. Female Infertility and Antioxidants. Curr Womens Health Rev. 2010;6:8495. DOI: $10.2174 / 157340410791321381$

Sharma RK, Agarwal A. Role of reactive oxygen species in male infertility. Urology 1996;48:835-50. PMID: 8973665 DOI: $10.1016 /$ S0090-4295(96)00313-5

Sule JO, Erigbali P, Eruom L. Prevalence of infertility in women in a Southwestern Nigerian community. Afr J Biomed Res 2008;11:225-7.

Tola EN, Mungan MT, Uğuz AC, Naziroğlu M. Intracellular $\mathrm{Ca} 2+$ and antioxidant values induced positive effect on fertilisation ratio and oocyte quality of granulosa cells in patients undergoing in vitro fertilisation. Reprod Fertil Dev. 2013;25:746-52. PMID: 22954014 DOI: 10.1071/RD12144

Tranquilli AL, Bezzeccheri V, Giannubilo SR, Scagnoli C, Mazzanti L, Garzetti GG. Amniotic vascular endothelial growth factor (VEGF) and nitric oxide (NO) in women with subsequent preeclampsia. Eur J Obst Gynecol Reprod Biol. 2004;113:17-20. DOI: $10.1016 /$ S0301-2115(03)00369-5 
Tsai-Turton M, Luderer U. Opposing effects of glutathione depletion and follicle-stimulating hormone on reactive oxygen species and apoptosis in cultured preovulatory rat follicles. Endocrinology. 2006;147:1224-36. PMID: 16339198 DOI: $10.1210 /$ en.2005-1281

Uadia PO, Emokpae AM. Male infertility in Nigeria: A neglected reproductive health issue requiring attention. J Basic Clin Reprod Sci. 2015;4:45-53. DOI: $10.4103 / 2278-960 X .161042$

Umezulike AC, Efetie ER. The psychological trauma of infertility in Nigeria. Int J Obstet Gynaecol. 2004;84:178-80. PMID: 14871526 DOI: 10.1016/S0020-7292(03)00316-3

Ursini F, Heim S, Kiess M, Maiorino M, Roveri A, Wissing J, Flohé L. Dual function of the selenoprotein PHGPx during sperm maturation. Science. 1999;285:1393-6. PMID: 10464096 DOI: $10.1126 /$ science.285.5432.1393

Wang Y, Sharma RK, Falcone T, Goldberg J, Agarwal A. Importance of reactive oxygen species in the peritoneal fluid of women with endometriosis or idiopathic infertility. Fertil Steril. 1997;68:826-30. PMID: 9389810 DOI: $10.1016 / S 0015-0282(97) 00343-9$
WHO - World Health Organization. Infertility: A tabulation of available data on prevalence of primary and secondary infertility. Programme on material and child health and family planning division of family health. Geneva: World Health Organization; 1991.

WHO - World Health Organization. WHO Laboratory Manual for Examination and Processing of Human Semen and Sperm-Cervical Mucus Interaction. $3^{\text {rd }}$ ed. New York: Cambridge University Press; 1992.

Wu Y, Kajdacsy-Balla A, Strawn E, Basir Z, Halverson G, Jailwala P, Wang Y, Wang X, Ghosh S, Guo SW. Transcriptional characterizations of differences between eutopic and ectopic endometrium. Endocrinology. 2006;147:232-46. PMID: 16195411 DOI: 10.1210/en.2005-0426

Yu SL, Yap C. Investigating the infertile couple. Ann Acad Med Singapore. 2003;32:611-3.

Zini A, de Lamirande E, Gagnon C. Reactive oxygen species in semen of infertile patients: levels of superoxide dismutase- and catalase-like activities in seminal plasma and spermatozoa. Int J Androl. 1993;16:183-8. PMID: 8359932 DOI: 10.1111/j.1365-2605.1993.tb01177.x 